\title{
Effection of Organic Acids on Sandstone Densification in Shanxi Formation Coal Source Rocks in Ordos Basin
}

\author{
Zhang Hua \\ Shandong Huayu University of Technology, East Road of University, Dezhou 253034, China \\ Dezhouzhhua@163.com
}

Keywords: coal source rock, organic acid, tight sandstone

\begin{abstract}
By means of core observation, conventional thin slice, cathodoluminescence, scanning electron microscopy, and basin simulation, the environment cause of the sandstone micropore in the reservoir were analyzed, the organic fluid and the densification development of the reservoir were studied. The results show that the source rock of coal is dominated by III kerogen. In the process of thermal evolution, a large number of aryl structure and oxygen containing functional groups fall off, III kerogen generates more organic acids than I, II kerogen, it has a stronger transformation effect on quartz sandstone. In the acidic micropore environment, quartz have multiple secondary enlargement and authigenic clay minerals occupied pores, the inorganic minerals (such as feldspar, cuttings) are dissolved. With the evolution of diagenesis, the pores are density, the organic acids in the source rocks of coal are the important reasons for the densification of sandstone.
\end{abstract}

\section{Introduction}

The studied area locates in the eastern Ordos Basin, the main part of the Yishan slope, the eastern side of the Jingbian gas field, and the east to Jinxi fold belt. The area is about $15000 \mathrm{~km}^{2}$, and more than 200 wells had been drilled. The target layer of the studied area was Permian Shanxi formation, and the tight sandstone gas reservoir has the characteristics of low porosity, low permeability, low abundance and large area distribution, and it has a state with many gas bearing systems, complex distribution, strong heterogeneity and low gas formation in some layers [1].

The main types of organic matter in the study area was coal type source rocks based on III kerogen. The main types of sandstone were quartz sandstone and lithic quartz sandstone, with some thin layers of coal and dark charcoal mudstones, and siliceous cementation developed widely, quartz developed the secondary enlargement. The main focus of previous research on the Shanxi formation of the Ordos Basin mainly concentrated on the sedimentary characteristics and development model [2], the reservoir classification evaluation [3], diagenesis and the gap evolution analysis[4], it was relatively weak to the study of the sandstone densification by the organic inorganic interaction of the reservoir. On the basis of previous work, we first described the source of organic acids in coal source rocks by means of conventional thin film, polarizing and cathodoluminescence, and then described the organic acid content and porosity change at the stage of diagenesis, and analyzed the diagenesis, mechanical compaction and siliceous cementation. Finally, the formation mechanism of tight sandstone in diagenetic stage was simulated and analyzed. The purpose was to reveal the organic acids in coal source rocks, the organic acids was the direct cause for quartz secondary enlargement, and it eventually leads to the development of sandstone densification.

\section{Formation of acid microporous environment}

\subsection{Source of organic acids}

The coal source rocks in the Shanxi formation in the eastern Ordos Basin were rich in terrestrial plants and aquatic plants. After the death of the plants, various functional groups were condensed into humus (hu min su, humic acid) under the action of chemical and microorganism. Humic type 
organic matter was the main source of organic matter in the source rocks of coal. The humic type of organic matter was the main source of formation of type III kerogen. Type III kerogen was a prerequisite for producing a large amount of organic acids. In the process of thermal evolution, there were plenty of aryl structures and oxygen functional group III kerogen. III kerogen formed more organic acids in the process of hydrocarbon generation than I, II kerogen. Oxygen evolved from the evolution of kerogen was mainly released as organic acids [5].

\subsection{Source of organic acids}

Organic fluids in the early diagenetic stage of Ordos Basin were mainly dissolved in feldspar minerals. Huang Si Jing and domestic and foreign scholars had shown that there were many types of short chain organic acids which were mainly acetic acid in the reservoir formation water [6]. Most scholars believed that the organic acids in the reservoir were derived from the adjacent hydrocarbon source rocks and dissolve the aluminosilicate and carbonate mineral in the reservoir [7]. With the increase of thermal evolution, III kerogen side chain and functional group gradually break up in the late stage of diagenetic thermal evolution. Deoxidization produced a large number of short chain fatty acids (such as acetic acid, propionic acid, $\mathrm{C}_{1}-\mathrm{C}_{10}$ positive structure and isomeric spindle acid and $\mathrm{C}_{2}-\mathrm{C}_{9}$ two spindle acid), alcohols, oxalic acid, citric acid, acetic acid, o-phthalic acid, two formic acid, neighbouring, quinol, aromatic compounds, aldehydes, ketones, ethers, benzoic acids. The organic acids in the formation water were mainly monoacids, which were mainly short chain fatty acids (mainly acetic acid and propionate), including benzene, phenol, naphthenic acid, hydrocarbon and other [8].

During the early diagenesis stage, in the process of plant marshing, the cellulose was decomposed into hydroxyl acid in the plant and the lignin was transformed into aromatic and aliphatic acids and the medium environment was hydrolyzed and acidified. During the middle diagenetic stage, humic type kerogen oxidized. When the formation temperature was higher than $120^{\circ} \mathrm{C}$, organic acids began to decarboxylation and the carboxylic acid concentration increased. In the late diagenetic stage, humic kerogen was mature and a large number of carboxyl groups fall off to form oxalic acid, citric acid, salicylic acid, acetic acid, acetone series compounds and short chain fatty acids (such as acetic acid, propionic acid, $\mathrm{C}_{1}$ to $\mathrm{C}_{10}$ positive structure and isomeric carboxylic acid and two meta carboxylic acid of $\mathrm{C}_{2}$ to $\mathrm{C}_{9}$ ), micro pore environment was acid, peak gas production stage, the acidity acid weakened.

\section{Reservoir rock characteristics}

\subsection{Petrological characteristics of reservoir}

The data of more than 1000 pieces of rock slices of 100 wells in the Shanxi formation of the upper Paleozoic were collected, and the basic characteristics of the composition, species, content and type of sandstone debris in the reservoir of the formation layer of the Shanxi formation were classified. The main sandstone types of Shanxi formation in the study area were quartz sandstone and lithic quartz sandstone, because of different regional differences, the types of sandstone in the main different layers were different. There were some thin layers of coal and dark carbonaceous mudstones in the sandstone. The siliceous cementation in the two types of sandstone was very common, the quartz developed secondary enlargement, especially the second period, while the pores were rich in clay minerals (kaolinite).

The analysis of the Shanxi formation in the Shanxi group is shown in Figure 1. The proportion of sandstone types in the reservoir sandstone showed that the proportion of quartz sandstone is $45 \%$, the proportion of quartz sandstone was $52 \%$, and the proportion of quartz in quartz sandstone was $78 \%-80 \%$, and the rock debris (volcanic, sedimentary and metamorphic rock) accounted for the proportion of quartz sandstone. The proportion was $10 \%-12 \%$, the proportion of kaolinite in the fillings was $4 \%-5 \%$, the proportion of water cloud mother was $1 \%-3 \%$, the proportion of siliceous material was $3-4 \%$, the proportion of calcite was $0-1 \%$, the proportion of quartz content in the lithic quartz sandstone was $60 \%-75 \%$, the proportion of the metamorphic rock debris was $8 \%-18 \%$, 
magmatic rock and mud debris. For example, the proportion of feldspar in $2-3 \%$ was $0 \%-1 \%$, but the feldspar "mould" which was metasomatic by kaolinite and calcite were seen.

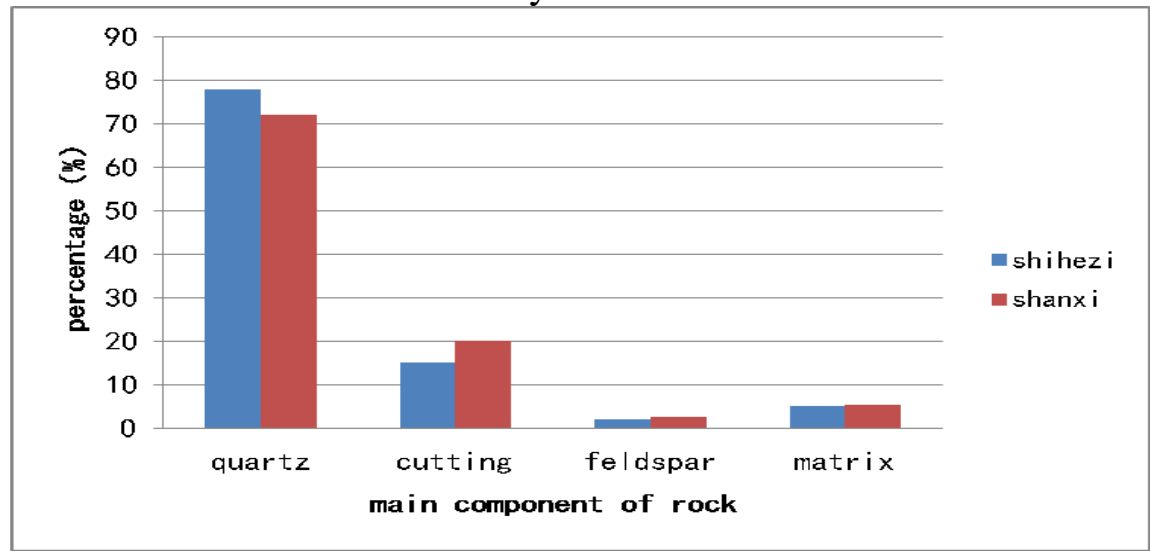

Figure 1 Average content of debris composition in the Ordos Basin.

\subsection{Petrological characteristics of reservoir}

The pore type of the target layer in the Ordos Basin was statistically analyzed. The primary pore was mainly the formation and preservation of the pore when the debris particles were deposited from the original deposit. It had been found that the primary pores are almost nonexistent.

The pores in the sandstone reservoirs in the study area often occur in combination form, the reservoir of Shihezi Formation was mainly composed of residual primary intergranular pores, intercrystalline pores, and a small number of miscellaneous dissolution pores. In the reservoir of Shanxi formation, the pore type of the cuttings dissolved in the pore was large, and the pore type was mainly dissolved pore, which was a constructive pore type of the reservoir, so the proportion of the pore types was less than the intergranular dissolution pore and the intragranular dissolution pore. The pores were shown in Figure 2.
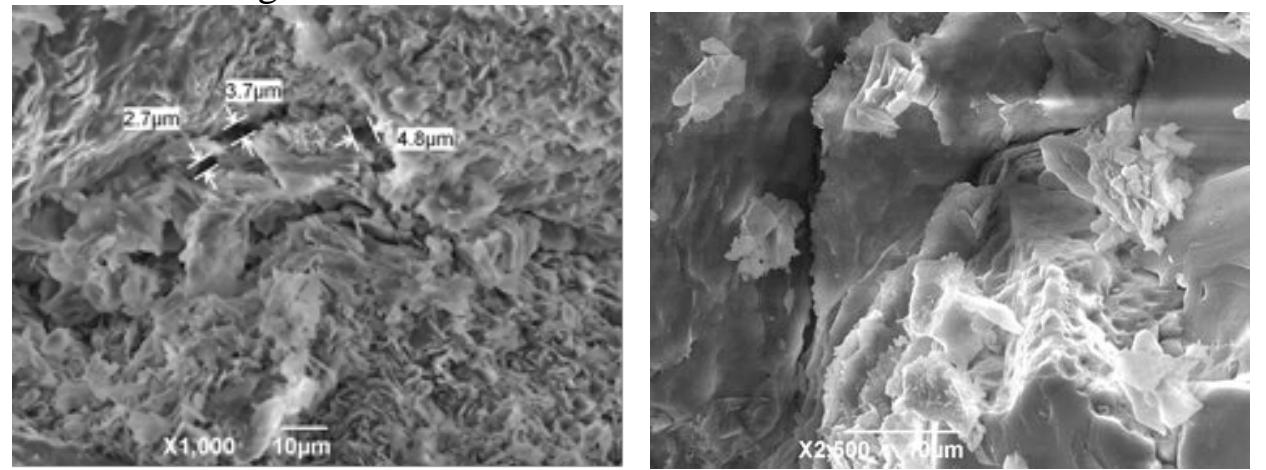

a) Y4xx Shihezi-Shanxi formation, Corrosion hole, $\times 1000$ b) Y4xx Shanxi formation, Intergranular pore, $\times 2500$

Figure 2 Microscopic characteristics of pore types in the Ordos Basin.

\section{Organic acid and microgap diagenetic environment}

\subsection{Transformation of organic acids to diagenetic minerals}

The effect of organic acids on the stability of inorganic minerals was mainly through the provision of a large amount of $\mathrm{H}^{+}$, complexation and so on to change the solubility of minerals. The experimental data showed that organic acid anions have an important effect on the $\mathrm{PH}$ of reservoir pore water [9]. It was widely proved by previous simulation experiments that the complex of organic fluids, such as calcium, magnesium, aluminum and silicon, had been precipitated, and the complexes of calcium, magnesium, aluminum and silicon had been detected by the experimenta 1[10]. The release of organic acids eventually leaded to densification of reservoirs. Therefore, the formation of organic acids in coal derived source rocks were of great significance for the densification and development of sandstone reservoirs. 


\subsection{Effect of organic acids on the microporous environment}

The source rocks of Shanxi formation in the eastern part of Ordos Basin were the mainly sources of organic acids in the source rocks of coal system, which were III kerogen. III kerogen had a higher oxygen content in III kerogen than I and II kerogen. Under acidic conditions, the soluble silicate minerals such as debris and feldspar were dissolved, which provided a siliceous source of secondary quartz and was accompanied by the formation of authigenic clay minerals such as kaolinite. Therefore, the organic acids in the source rocks of the coal measures in Shanxi formation caused the siliceous cementation, and it was widespread development in the acidic microporous environment. The pore was occupied by clay minerals and siliceous cements in the evolution stage of the reservoir (shown in Figure 3), and the sandstone densified.
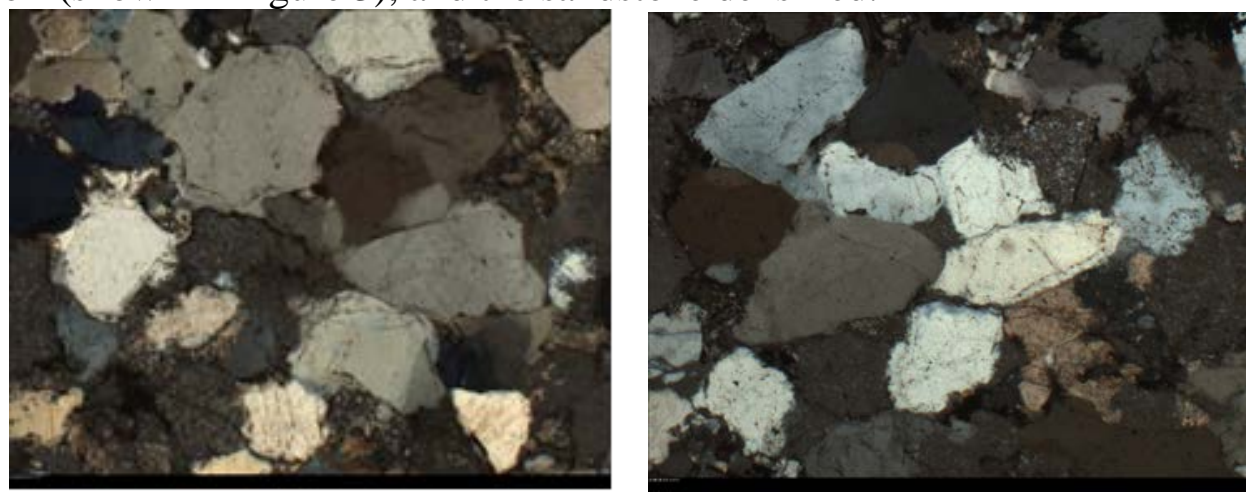

a) Y4xx, Shihezi formation, particle line contact, $\times 50$ b) Y4xx , Shihezi formation, particle line contact, $\times 50$

Figure 3 The sandstone of the target layer in the study area.

\section{Densification and development of diagenesis and reservoir}

The evolution of reservoir in diagenetic stage had a good correspondence with the evolution of organic matter (shown in Table 1). The change of organic acid concentration and the change of pore water medium properties affect the change characteristics of inorganic minerals in the reservoir. There were a series of changes in the authigenic minerals and clay minerals of the clastic reservoirs. In the acid microporous environment controlled by organic acids, the soluble inorganic minerals such as feldspar and other silicate minerals and volcaniclastic minerals were dissolved, producting kaolinite and its siliceous products, and thus provided a siliceous source for the secondary increase of quartz. Obviously, it had a direct relationship with the release and distribution of organic acids in the reservoir.

Table 1 The sequence of diagenesis in the study area.

\begin{tabular}{|c|c|c|c|c|c|}
\hline \multirow{3}{*}{$\mathrm{N}_{\text {Diagenesis }}^{\text {Diagenetic }}$ stage } & \multicolumn{5}{|c|}{ Diagenetic stage } \\
\hline & \multicolumn{2}{|c|}{ Early } & \multicolumn{3}{|c|}{ Late } \\
\hline & $\mathrm{A}$ & B & A & $\mathrm{B}$ & $\mathrm{C}$ \\
\hline Humic acid & & & & & \\
\hline Mechanical compaction & & & & & \\
\hline Carboxylic acid generation & & & & & \\
\hline Pressure dissolution & & & & & \\
\hline Secondary pores & & & & & \\
\hline Secondary increase of quartz & & & & & \\
\hline Authigenic kaolinite & & & & & \\
\hline Ferric dolomite & & & & & \\
\hline Iron calcite & & & & & \\
\hline
\end{tabular}

At the end of the early diagenetic stage, due to compaction and early siliceous cementation, quartz sandstone decreased in original porosity of the reservoir to $15.47 \%$. In the late diagenetic stage A, compaction and siliceous cementation resulted in further reduction of reservoir porosity to 
$10.94 \%$, in late diagenetic stage $\mathrm{B}$, compaction and siliceous cementation, resulted in further reduction of reservoir porosity to $8.23 \%$, in late diagenetic stage $\mathrm{C}$, further decrease of porosity to $5.84 \%$, and reservoir compaction.

\section{Simulation analysis}

The distribution of thermal evolution of organic matter in the upper Paleozoic strata in the eastern Ordos Basin was influenced by the distribution of paleo geothermal distribution. The formation and discharge of natural gas in the upper Paleozoic strata in the eastern Ordos basin can be divided into 2 main stages, influenced by the pattern of the thermal evolution of organic matter. The first hydrocarbon generation stage was mainly from Late Triassic to early Cretaceous, and most of the basin entered the hydrocarbon generation threshold and entered the stage of early organic hydrocarbon generation thermal evolution. The second secondary hydrocarbon generation stage in the upper Paleozoic strata in the eastern Ordos Basin is from the late Cretaceous to the present time. The paleo geotemperature had increased rapidly. After that, the tectonic evolution of the basin is in the stage of continuous uplift and change. The organic inorganic interaction formed by organic acid injection is the main factor affecting porosity and reservoir densification (shown in Figure 4).

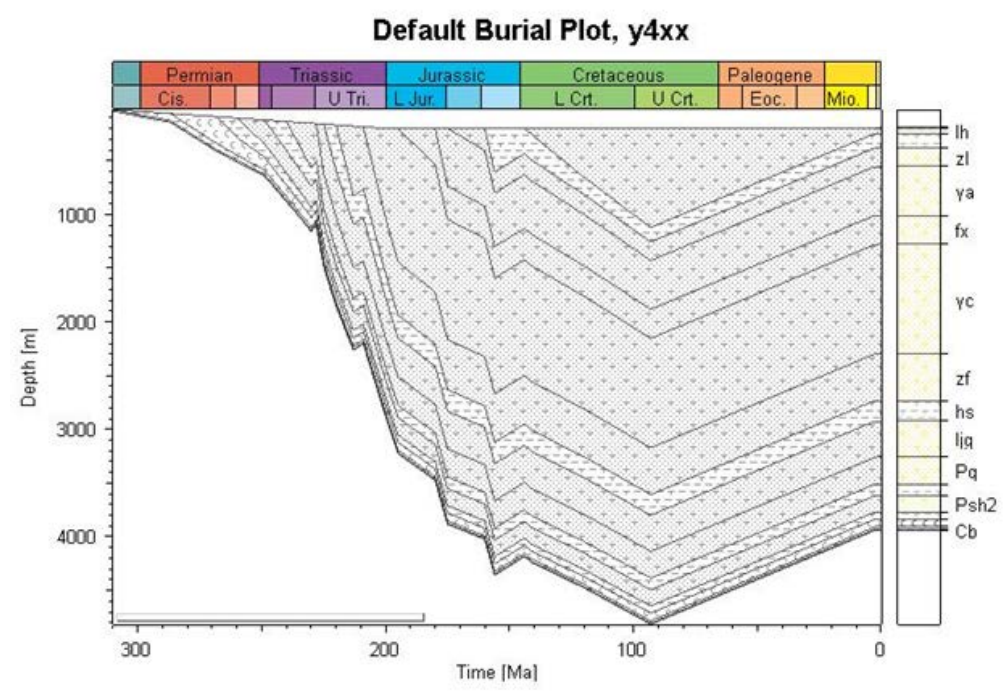

Figure 4 Sedimentary tectonic evolution of the upper Paleozoic Erdos Basin.

\section{Conclusions}

1) The formation of organic matter in the Shanxi formation of the eastern Ordos Basin was a coal source rock with III kerogen. III kerogen can release more organic acid fluid than I and II kerogen, which led to the acidity of the pore space environment of coal source rocks.

2) Shanxi formation in the eastern of Ordos Basin was a typical low porosity and permeability tight reservoir, and the sandstone type was mainly quartz quartzite sandstone. Organic acids dissolve the inorganic minerals such as feldspar, rock and other minerals. The secondary increase of quartz occurred in multiple periods. The authigenic clay minerals occupy the pore space, and the sandstone of the Shanxi formation in the study area was mechanically compacted and strongly siliceous cementing, and the pore densification was developed.

3) At the end of the early diagenetic stage, due to compaction and early siliceous cementation, quartz sandstone decreased in original porosity of the reservoir to $15.47 \%$. In the late diagenetic stage A, compaction and siliceous cementation resulted in further reduction of reservoir porosity to $10.94 \%$, in late diagenetic stage $\mathrm{B}$, compaction and siliceous cementation, reservoir porosity reduced to $8.23 \%$, in late diagenetic stage $\mathrm{C}$, porosity further decreased to $5.84 \%$, and reservoir compaction. 


\section{References}

[1] Zhang S. C, Mi J. K, Liu L. H, et. al. The geological characteristics and accumulation process of China tight sandstone coal forming gas reservoir: taking the upper Paleozoic and the Xujiahe group gas reservoir in the Ordos Basin as an example. Geoscience: Journal of China University of Geoscience,2009,36(3):320-330.

[2] Wang R. G. Microcosmic characteristics of river facies and delta facies reservoir. Xi'an Northwest University,2013.

[3] Qi T. T, Qi X. L, Lu Y. P. Shan23 Formation in Su77 reservoir characteristics and classification evaluation. Petroleum Geology and Engineering,2013,27(6):51-54.

[4] Wang X. C, Luo J. L, Li W. H, et. al. The quantitative analysis of diagenesis and pore evolution of the reservoirs Shan 23 in Su77-Zhao51 of the Ordos Basin, The Modern Geology, 2017,31(3), 565-573.

[5] Birth'f. BJlykke K. Organic acids from source rock maturation: generation potentials, transport mechanisms andrelevance for mineral diagenesis. Applied Geochemistry,1993,8, 25-337.

[6] Huang S. J, Yang J. J, Zhang W. Z, et al. Experimental study of acetic acid on feldspar dissolution under different temperature conditions. Acta Sedimentica Sinica,1995,13(1),7-17.

[7] Huang S. J, Wu W. H, Liu J, et. al. The role of human water in the formation of secondary pores in clastic rocks - an example of the permian extension group in the Ordos Basin. Geoscience-China Geology Journal,2003,28(4),419-424.

[8] Zheng J. M, Ying F. Sandstone reservoir characteristics and diagenetic model of coal measures (acidic water medium). Acta Sinica,1997,18(4),19-24.

[9] Mei B. W, Yang W. K. Reservoir geochemistry translation set, Xi'an Northwestern University Press,1991.1-241.

[10] Willev L M. Kharaka Y K. Presser T S etal. Short chain aliphatic acid anions in oil field waters and their contribution to the measured alkalinity, Geochirmica et Cosmochimica Acta,1975, 39, 1707-1711. 